\title{
Safety of transcranial direct current stimulation in a patient with deep brain stimulation electrodes
}

\author{
Segurança da estimulação transcraniana por corrente contínua em uma paciente com \\ implante de eletrodos de estimulação cerebral profunda
}

Aline lannone', Nasser Allam', Joaquim P. Brasil-Neto²

\begin{abstract}
Background: Transcranial direct current stimulation (tDCS) has been investigated in movement disorders, making it a therapeutic alternative in clinical settings. However, there is still no consensus on the most appropriate treatment protocols in most cases, and the presence of deep brain stimulation (DBS) electrodes has been regarded as a contraindication to the procedure. We recently studied the effects of cerebellar tDCS on a female patient already undergoing subthalamic nucleus deep brain stimulation (STN-DBS) for generalized dystonia. She also presented with chronic pain and depression. With STN-DBS, there was improvement of dystonia, and botulinum toxin significantly reduced pain. However, depressive symptoms were worse after STN-DBS surgery. Methods: Neuromodulation with 2 mA anodal cerebellar tDCS was initiated, targeting both hemispheres in each daily 30 minute session: 15 minutes of left cerebellar stimulation followed by 15 minutes of right cerebellar stimulation. The DBS electrodes were in place and functional, but the current was turned off during tDCS. Results: Although our goal was to improve dystonic movements, after 10 tDCS sessions there was also improvement in mood with normalization of Beck Depression Inventory scores. There were no complications in spite of the implanted STN-DBS leads. Conclusion: Our results indicate that tDCS is safe in patients with DBS electrodes and may be an effective add-on neuromodulatory tool in the treatment of potential DBS partial efficacy in patients with movement disorders.
\end{abstract}

Keywords: Transcranial direct current stimulation; deep brain stimulation; movement disorders.

\section{RESUMO}

Descrição: A estimulação transcraniana por corrente contínua (ETCC) tem sido investigada nos distúrbios de movimento, tornando-a uma alternativa terapêutica no contexto clínico. Contudo, não há consenso quanto aos protocolos mais apropriados na maioria dos casos e a presença de eletrodos de estimulação cerebral profunda (ECP) é geralmente considerada uma contraindicação. Recentemente, estudamos os efeitos da ETCC cerebelar em uma paciente do sexo feminino com implante de eletrodos de estimulação cerebral profunda (ECP) para distonia generalizada. Ela também apresentava dor crônica e depressão. A ETCC foi realizada dois anos após o implante de eletrodos de ECP. Com a ECP houve melhora da distonia e a toxina botulínica reduziu a dor. Contudo, os sintomas depressivos pioraram após a cirurgia de ECP. Métodos: Foi proposta ETCC cerebelar anódica de 2mA, sobre os dois hemisférios em cada sessão de $30 \mathrm{~min}$ : 15 min de ETCC cerebelar esquerda seguida de 15min de ETCC cerebelar direita. Resultados: Embora o nosso objetivo tenha sido melhorar os movimentos distônicos, após 10 sessões de ETCC houve melhora também do humor da paciente. Não houve nenhuma complicação, apesar da presença de eletrodos de ECP. Conclusão: Nossos resultados apontam para a segurança da tDCS e sua aplicação potencial e efetiva como ferramenta neuromodulatória adicional no tratamento de possíveis sintomas persistentes após a ECP em pacientes com distúrbios de movimento.

Palavras-chave: Estimulação transcraniana por corrente contínua; estimulação cerebral profunda; transtornos do movimento.

Although there are many possible applications for noninvasive brain stimulation in neurological and neuropsychiatric diseases, there are still concerns about the use of transcranial direct current stimulation (tDCS) in patients with intracranial implants, such as deep brain stimulation (DBS) electrodes.

\footnotetext{
${ }^{1}$ Universidade de Brasília, Laboratório de Neurociência e Comportamento, Instituto de Biologia, Brasília DF, Brasil; ${ }^{2}$ Universidade de Brasília, Departamento de Ciências Fisiológicas, Instituto de Biologia, Brasília DF, Brasil.'
}

Joaquim P. Brasil-Neto iD http://orcid.org/0000-0003-1678-6311; Aline lannone iD https://orcid.org/0000-0002-8717-6564; Nasser Allam https://orcid.org/0000-0002-4041-5185

Correspondence: Aline lannone; Universidade de Brasília, Laboratório de Neurociência e Comportamento, Instituto de Biologia; CFS (bloco G) - salas G1-10/8 e G1-15/8, Campus Universitário Darcy Ribeiro; 70910-900 Brasília DF, Brasil; E-mail: draalineiannone@gmail.com

Conflict of interest: There is no conflict of interest to declare.

Received 01 July 2018; Received in final form 19 November 2018; Accepted 04 December 2018. 
However, due to the invasive nature of DBS, noninvasive brain stimulation techniques, such as tDCS, have been investigated in movement disorders, making it a therapeutic alternative in clinical settings.

Deep brain stimulation, e.g. of the subthalamic nucleus (STN-DBS), may be effective in movement disorders ${ }^{1,2,3}$, such as in patients with primary dystonia manifestations ${ }^{4-6}$ measured by the Burke-Fahn-Marsden Dystonia Rating Scale, and may improve their quality of life in terms of physical functioning, bodily pain, and mental health measured by the 36-Item Short-Form General Health Survey ${ }^{4}$ Improvement has been reported in patients with medically refractory isolated dystonia, even 12 and 36 months after STN-DB surgery 5 . Similar effective results with bilateral STN-DBS for the treatment of movement disorders ${ }^{6,7}$ have suggested that bilateral STN-DBS may also be an interesting treatment option for cervical and generalized dystonia, improving dystonia symptoms, and improving mental health, even in patients who have already undergone bilateral pallidotomy ${ }^{8}$.

Dystonia is a movement disorder in which sustained muscle contractions give rise to abnormal postures or involuntary movements ${ }^{9,10}$. Evidence indicates that psychiatric morbidity is higher in patients with dystonia than in patients with other chronic diseases ${ }^{11}$, and depression, anxiety and obsessive-compulsive disorder are the most common psychiatric diagnoses in dystonia patients, with moderate to severe depression experienced by about a quarter of the patients with dystonia ${ }^{12}$. In the past, a few studies have drawn attention to a worrisome side effect, namely the worsening of mood and development of transient depression after DBS surgery ${ }^{4}$ in patients with Parkinson's disease ${ }^{13}$. However, a direct relationship with DBS has never been established ${ }^{14,15}$. A noninvasive neuromodulatory tool, such as tDCS, could be a potential add-on therapy to enhance the effects of DBS. However, there is still no consensus on the most appropriate tDCS treatment protocols for most movement disorder patients. In addition, the presence of DBS electrodes is generally regarded as a contraindication to tDCS. Exclusion of patients with preexisting implants, especially intracranial implants, is common in tDCS trials, as a precautionary measure $^{16}$. However, to the best of our knowledge, to date there has been no reported evidence of injury to a patient with an intracranial implant and no theoretical risk of injury based on computerized modeling.

We aimed to explore the safety of add-on tDCS in a 45-year-old female patient already undergoing STN-DBS for generalized dystonia, which was maximal in the neck and trunk, with relative limb sparing. Walking was possible, but neck dystonia forced her to turn her head upward and to the left, making it difficult to look straight ahead. Speech was also extremely forceful. She also presented with chronic neck and shoulder pain and mild depression. With DBS, there was partial but clinically-significant improvement, especially in neck dystonia and speech, and botulinum toxin injections significantly reduced pain. However, depressive symptoms and anxiety were worse after the DBS surgery, probably because of high expectations by the patient and postoperative persistence of a few dystonic symptoms (although there was objective improvement).

\section{METHODS}

In an attempt to further alleviate the patient's dystonic movements, compassionate use of tDCS was prescribed. A commercially available transcranial direct current stimulator (TransCranial", Hong Kong, China) was used to deliver $2.0 \mathrm{~mA}$ for 30 minutes per session through saline-soaked sponge electrodes (surface $35 \mathrm{~cm}^{2}$ ). Electrode placement on the scalp was determined using the International 10-20 EEG system.

Anodal cerebellar tDCS at $2 \mathrm{~mA}$ was initiated, targeting both hemispheres in each daily 30 minute session: 15 minutes of left cerebellar stimulation (O1-FC4) followed by 15 minutes of right cerebellar stimulation (O2-FC3), from Monday to Friday for three weeks (15 sessions). Care was taken to keep the electrodes and wires away from surgical skull defects and DBS leads. The location and polarity of the electrodes, number of sessions, and current intensity were chosen on the basis of previously-reported results demonstrating that $2 \mathrm{~mA}$ of anodal tDCS over the cerebellum for 15-20 minutes is capable of improving certain movement disorders ${ }^{17}$, such as Parkinson's disease, by improving the levodopa-induced dyskinesias $^{18,19}$, cervical dystonia ${ }^{20,21}$, and other neurological disorders including cerebellar ataxia $22,23,24,25$. Informed consent was obtained from the patient prior to all procedures. The patient was evaluated by a neurologist (NA) and a neuropsychologist (AI) during the entire tDCS treatment.

\section{RESULTS}

After STN-DBS surgery, the patient reported substantial improvement one month after the surgery, compared with her previous condition. The most striking changes were in neck dystonia and speech. However, the patient also reported worsening depression and anxiety, which increased even two to three years after DBS surgery. Although our main goal was to further improve dystonic movements, after 10 tDCS sessions there was also improvement in mood according to the Beck Depression Inventory: the patient's score changed from 14 (mild mood disturbance) to 4 (normal score). There was also further improvement in generalized dystonia (which lasted for over 12 hours after each session), chronic pain and cognitive functions (executive function and attention), as evaluated by a neurologist specialized in movement disorders (NA) and a neuropsychologist (AI), who evaluated the patient and recorded videos before and after tDCS sessions to document any effects upon dystonia. The Table summarizes these findings. In spite of the presence of DBS electrodes, the 
Table. Transcranial direct current stimulation (tDCS) effects on different neuropsychological and neuropsychiatric parameters in a dystonia patient before and after 10 tDCS sessions.

\begin{tabular}{|c|c|c|}
\hline Instruments and measures & Before tDCS & After tDCS \\
\hline \multicolumn{3}{|l|}{ Neuropsychiatric symptoms and psychopathology } \\
\hline Beck Depression Inventory, n/11 & 14 & 4 \\
\hline Beck Anxiety Inventory, n/11 & 21 & 1 \\
\hline \multicolumn{3}{|l|}{ Activities of Daily Living } \\
\hline Pfeffer's functional assessment questionnaire, n/8 & 2 & 0 \\
\hline Barthel index, $n \bullet 91$ & 95 & 100 \\
\hline \multicolumn{3}{|l|}{ Global cognition score } \\
\hline Mini-mental state examination, $\mathrm{n} / 26$ & 29 & 30 \\
\hline \multicolumn{3}{|l|}{ Executive and attention functions } \\
\hline Digit span forward (Wechsler adult intelligence scale), n/16 & 7 & 7 \\
\hline Digit span backward (Wechsler adult intelligence scale), n/14 & 4 & 6 \\
\hline Digit span (forward - backward), n/4 & 3 & 1 \\
\hline Digit span (forward + backward), n/30 & 11 & 13 \\
\hline \multicolumn{3}{|l|}{ Stroop color-word test Victoria } \\
\hline Total errors & 5 & 1 \\
\hline Completion time (seconds) & 79 & 66 \\
\hline
\end{tabular}

Five digits test (FDT)

Automatic attentional processes (attention and processing speed)

FDT reading (seconds), $\mathrm{n} / 23.9$

Errors, $n / 0$

$33 \quad 29$

FDT counting (seconds), $\mathrm{n} / 27.1$

0

Errors, $n / 0$

36

Controlled attentional processes (selective attention and executive functions)

$\begin{array}{lcc}\text { FDT choosing (seconds), } n / 41.7 & 49 & 47 \\ \text { Errors, } n / 0,7 & 3 & 1 \\ \text { FDT shifting (seconds), } n / 53.6 & 98 & 49 \\ \text { Errors, } n / 1,5 & 6 & 2 \\ \text { Inhibitory control (choosing - reading; sec), } n / 17.8 & 16 & 18 \\ \text { Cognitive shifting (shifting - reading; sec), } n / 29.7 & 65 & 20\end{array}$

Raw scores/reference value according to patient age and schooling. Trial 1: 1st attempt at list A recall; Trial 5: 5th attempt at list A recall; Delayed recall: 7th attempt at list A recall; Recognition: recognition of list A; list B: list of interference; LOT: learning over trials. Higher test scores indicate better performances, except for time measures, where high scores indicate poor performance.

tDCS application was uneventful. There were no post-session headaches, skin redness or electrolytic burns, or signs of autonomic dysfunction (blood pressure and heart rate did not change during tDCS sessions, and there were no syncope episodes, pallor or excessive sweating). Moreover, executive function and attention were not adversely affected; on the contrary, they improved after tDCS sessions. Therefore, our case study demonstrated that frontocerebellar tDCS may be performed safely, even in the presence of DBS electrodes.

\section{DISCUSSION}

The main conclusion to be drawn from this case study is that tDCS may be safely performed in patients with implanted deep brain stimulation electrodes, in spite of the traditional recommendation that such patients be excluded from clinical tDCS trials.

The mechanism of action of tDCS is such that no direct neuronal depolarization occurs ${ }^{26}$; currents that actually reach the brain are attenuated by scalp and skull resistance. This is in sharp contrast to what happens in the case of transcranial magnetic stimulation, which employs a strong magnetic field and is capable of inducing intracranial currents of enough magnitude to cause neuronal firing of action potentials ${ }^{27,28}$. While transcranial magnetic stimulation should be avoided in patients with intracranial metallic implants (including DBS electrodes) due to the danger of electromagnetically-induced undesirable currents, tDCS should be safe, as long as the stimulation electrodes are kept away from the DBS leads or skull burr-holes, as in the present case. 
Esmaeilpour et al. ${ }^{29}$ have recently measured currents in DBS electrodes in the subthalamic nucleus and nucleus accumbens in patient volunteers after brief tDCS applied to O2 (international 10-20 system) with a supraorbital reference. They also measured currents in implanted electrodes in the motor cortex. Their results showed that voltages produced by tDCS electrodes were smaller in DBS electrodes in comparison with the cortical target. There were no untoward effects, but their tDCS stimulation was very brief (30 seconds), while our patient underwent 20 minute-sessions.

Our patient also showed normalization of her depression scores. A recent study by Deng et al. ${ }^{4}$ has shown that STN-DBS is effective and very safe in generalized dystonia; in their series, only $2 / 14$ patients experienced depression after surgery, and then only transiently. Therefore, it is unlikely that our patient's long-standing mild depression was related to DBS. But how does one explain mood improvement after cerebellar tDCS? A recent literature review cites evidence of the physiological role of the cerebellum in maintaining mood as well as its implication in the pathophysiology of bipolar disorder and major depressive disorder. Minichino et al. ${ }^{30}$ suggested the cerebellum has roles in cognition, mood and behavior ${ }^{31,32,33}$. In their study, they pointed to the role of the cerebellum in modulating emotional processing, providing strong evidence from clinical and electrophysiological studies to support their view. They concluded that the cerebellum seems to be a sort of emotional "pacemaker."

As to the effect of cerebellar tDCS, another recent study by Newstead et al. ${ }^{34}$ found that frontocerebellar tDCS was able to improve mood, even in non-depressed participants, both acutely and after repeated sessions. However, the effect observed in this case study, although interesting, might have been due to a placebo effect and needs to be further examined in future studies for a better understanding of its consistency and potential mechanisms.

These findings indicate a potential application for tDCS as a safe and effective add-on neuromodulatory tool after DBS treatment of patients with movement disorders, such as generalized dystonia.

\section{References}

1. Kleiner-Fisman G, Liang GS, Moberg PJ, Ruocco AC, Hurtig HI, Baltuch GH, et al. Subthalamic nucleus deep brain stimulation for severe idiopathic dystonia: impact on severity, neuropsychological status, and quality of life.J Neurosurg. $2007 \mathrm{Jul} ; 107(1): 29-36$. https://doi.org/10.3171/JNS-07/07/0029

2. Pastor-Gómez J, Hernando-Requejo V, Luengo-Dos Santos A, Pedrosa-Sánchez M, Sola RG. [Treatment of a case of generalised dystonia using subthalamic stimulation]. Rev Neurol. 2003 Sep;37(6):529-31. Spanish.

3. Sun B, Chen S, Zhan S, Le W, Krahl SE. Subthalamic nucleus stimulation for primary dystonia and tardive dystonia. Acta Neurochir Suppl (Wien). 2007;97(Pt 2):207-14. https://doi.org/10.1007/978-3-211-33081-4_23

4. Deng Z, Pan Y, Zhang C, Zhang J, Qiu X, Zhan S, et al. Subthalamic deep brain stimulation in patients with primary dystonia: A ten-year follow-up study. Parkinsonism Relat Disord. 2018 Oct;55:103-10. https://doi.org/10.1016/j.parkreldis.2018.05.024

5. Ostrem JL, San Luciano M, Dodenhoff KA, Ziman N, Markun LC, Racine CA, et al. Subthalamic nucleus deep brain stimulation in isolated dystonia: A 3-year follow-up study. Neurology. 2017 Jan;88(1):25-35. https://doi.org/10.1212/WNL.0000000000003451

6. Chou KL, Hurtig HI, Jaggi JL, Baltuch GH. Bilateral subthalamic nucleus deep brain stimulation in a patient with cervical dystonia and essential tremor. Mov Disord. 2005 Mar;20(3):377-80. https://doi.org/10.1002/mds.20341

7. Novak KE, Nenonene EK, Bernstein LP, Vergenz S, Cozzens JW, Rezak M. Successful bilateral subthalamic nucleus stimulation for segmental dystonia after unilateral pallidotomy. Stereotact Funct Neurosurg. 2008;86(2):80-6. https://doi.org/10.1159/000112428

8. Fonoff ET, Campos WK, Mandel M, Alho EJ, Teixeira MJ. Bilateral subthalamic nucleus stimulation for generalized dystonia after bilateral pallidotomy. Mov Disord. 2012 Oct;27(12):1559-63. https://doi.org/10.1002/mds.25127
9. Marsden CD, Harrison MJ. Idiopathic torsion dystonia (dystonia musculorum deformans). A review of forty-two patients. Brain. 1974 Dec;97(4):793-810. https://doi.org/10.1093/brain/97.1.793

10. Fahn S, Bressman SB, Marsden CD. Classification of dystonia. Adv Neurol. 1998;78:1-10.

11. Lewis L, Butler A, Jahanshahi M. Depression in focal, segmental and generalized dystonia.J Neurol. 2008 Nov;255(11):1750-5. https://doi.org/10.1007/s00415-008-0020-x

12. Jahanshahi M. Behavioral and psychiatric manifestations in dystonia. Adv Neurol. 2005;96:291-319.

13. Burkhard PR, Vingerhoets FJ, Berney A, Bogousslavsky J, Villemure JG, Ghika J. Suicide after successful deep brain stimulation for movement disorders. Neurology. 2004 Dec;63(11):2170-2. https://doi.org/10.1212/01.WNL.0000145603.48221.B5

14. Voon V, Krack P, Lang AE, Lozano AM, Dujardin K, Schüpbach M, et al. A multicentre study on suicide outcomes following subthalamic stimulation for Parkinson's disease. Brain. 2008 Oct;131(Pt 10):2720-8. https://doi.org/10.1093/brain/awn214

15. Weintraub D, Duda JE, Carlson K, Luo P, Sagher O, Stern M, et al. Suicide ideation and behaviours after STN and GPi DBS surgery for Parkinson's disease: results from a randomised, controlled trial.J Neurol Neurosurg Psychiatry. 2013 Oct;84(10):1113-8. https://doi.org/10.1136/jnnp-2012-304396

16. Brunoni AR, Nitsche MA, Bolognini N, Bikson M, Wagner T, Merabet L, et al. Clinical research with transcranial direct current stimulation (tDCS): challenges and future directions. Brain Stimul. 2012 Jul;5(3):175-95. https://doi.org/10.1016/j.brs.2011.03.002

17. França C, Andrade DC, Teixeira MJ, Galhardoni R, Silva V, Barbosa ER, et al. Effects of cerebellar neuromodulation in movement disorders: A systematic review. Brain Stimul. 2018 Mar-Apr;11(2):249-60. https://doi.org/10.1016/j.brs.2017.11.015

18. Ferrucci R, Bianchi M, Pittera D, Cortese F, Turrone R, Vergari M, et al. Effects of transcranial direct current stimulation (tDCS) on levodopa-induced dyskinesias in Parkinson's disease. Mov Disord. 2014;29 Suppl 1:641. 
19. Ferrucci R, Bocci T, Cortese F, Ruggiero F, Priori A.

Cerebellar transcranial direct current stimulation in neurological disease. Cerebellum Ataxias. 2016 Sep;3(1):16. https://doi.org/10.1186/s40673-016-0054-2

20. Bradnam LV, Frasca J, Kimberley TJ. Direct current stimulation of primary motor cortex and cerebellum and botulinum toxin a injections in a person with cervical dystonia. Brain Stimul. 2014 NovDec;7(6):909-11. https://doi.org/10.1016/j.brs.2014.09.008

21. Bradnam LV, Graetz LJ, McDonnell MN, Ridding MC. Anodal transcranial direct current stimulation to the cerebellum improves handwriting and cyclic drawing kinematics in focal hand dystonia. Front Hum Neurosci. 2015 May; 9:286. https://doi.org/10.3389/fnhum.2015.00286

22. Benussi A, Koch G, Cotelli M, Padovani A, Borroni B. Cerebellar transcranial direct current stimulation in patients with ataxia: $A$ double-blind, randomized, sham-controlled study. Mov Disord. 2015 Oct;30(12):1701-5. https://doi.org/10.1002/mds.26356

23. Grecco L, Duarte N, Marques V, Zanon N, Galli M, Fregni F, et al. Cerebellar transcranial direct current stimulation in a child with ataxic cerebral palsy: a case report. Gait \& Posture. 2015 Sep;42:S93-4. https://doi.org/10.1016/j.gaitpost.2015.06.171

24. Grecco LA, Oliveira CS, Duarte NA, Lima VL, Zanon N, Fregni F. Cerebellar transcranial direct current stimulation in children with ataxic cerebral palsy: A sham-controlled, crossover, pilot study. Dev Neurorehabil. 2017 Apr;20(3):142-8. https://doi.org/10.3109/17518423.2016.1139639

25. Benussi A, Dell'Era V, Cotelli MS, Turla M, Casali C, Padovani $A$, et al. Long term clinical and neurophysiological effects of cerebellar transcranial direct current stimulation in patients with neurodegenerative ataxia. Brain Stimul. 2017 Mar - Apr;10(2):24250. https://doi.org/10.1016/j.brs.2016.11.001

26. Nitsche MA, Paulus W. Excitability changes induced in the human motor cortex by weak transcranial direct current stimulation. J Physiol. 2000 Sep;527(Pt 3):633-9. https://doi.org/10.1111/j.1469-7793.2000.t01-1-00633.x
27. Barker AT, Jalinous R, Freeston IL. Non-invasive magnetic stimulation of human motor cortex. Lancet. 1985 May;1(8437):1106-7. https://doi.org/10.1016/S0140-6736(85)92413-4

28. Hallett M. Transcranial magnetic stimulation and the human brain. Nature. 2000 Jul;406(6792):147-50. https://doi.org/10.1038/35018000

29. Esmaeilpour Z, Milosevic M, Azevedo K, Khadka N, Navarro J, Brunoni A, et al. Intracranial voltage recording during transcranial direct current stimulation (tDCS) in human subjects with validation of a standard model. Brain Stimul. 2017 Jul;10(4):e72-5. https://doi.org/10.1016/j.brs.2017.04.114

30. Minichino A, Bersani FS, Bernabei L, Spagnoli F, Vergnani L, Corrado A, et al. Prefronto-cerebellar transcranial direct current stimulation improves visuospatial memory, executive functions, and neurological soft signs in patients with euthymic bipolar disorder. Neuropsychiatr Dis Treat. 2015 Aug;11:2265-70. https://doi.org/10.2147/NDT.S79108

31. Rapoport M, van Reekum R, Mayberg H. The role of the cerebellum in cognition and behavior: a selective review. J Neuropsychiatry Clin Neurosci. 2000;12(2):193-8. https://doi.org/10.1176/jnp.12.2.193

32. Schmahmann JD. The role of the cerebellum in cognition and emotion: personal reflections since 1982 on the dysmetria of thought hypothesis, and its historical evolution from theory to therapy. Neuropsychol Rev. 2010 Sep;20(3):236-60. https://doi.org/10.1007/s11065-010-9142-x

33. Schmahmann JD, Caplan D. Cognition, emotion and the cerebellum. Brain. 2006 Feb;129(Pt 2):290-2. https://doi.org/10.1093/brain/awh729

34. Newstead S, Young H, Benton D, Jiga-Boy G, Andrade Sienz ML, Clement RM, et al. Acute and repetitive frontocerebellar tDCS stimulation improves mood in non-depressed participants. Exp Brain Res. 2018 Jan;236(1):83-97. https://doi.org/10.1007/s00221-017-5109-y 